\title{
Sensitivity Analysis of Fleet Size for Dynamic Headway-Based Control Method Performance in terms of Passengers' Experience
}

\author{
Shidong Liang $\mathbb{D},{ }^{1}$ Hu Zhang $\mathbb{D},{ }^{1}$ Minghui Ma $\mathbb{D}^{2},{ }^{2}$ and Shengxue He $\mathbb{D}^{1}$ \\ ${ }^{1}$ Business School, University of Shanghai for Science and Technology, Shanghai, China \\ ${ }^{2}$ School of Mechanical and Automotive Engineering, Shanghai University of Engineering Science, Shanghai, China \\ Correspondence should be addressed to Minghui Ma; maminghui1989@hotmail.com
}

Received 21 February 2019; Revised 13 June 2019; Accepted 12 November 2019; Published 6 January 2020

Academic Editor: Zhi-Chun Li

Copyright (c) 2020 Shidong Liang et al. This is an open access article distributed under the Creative Commons Attribution License, which permits unrestricted use, distribution, and reproduction in any medium, provided the original work is properly cited.

\begin{abstract}
The headway-based control method is usually used to regulate the bus headways to improve the bus operation. However, these control methods only focus on equalizing bus headways, neglecting analysis for STD (standard deviation) of passengers on the buses. Therefore, in order to fix this gap, this paper analyzed performance of the control method in terms of regulating bus headways and number of passengers on the buses under variable number of buses on the route. First, as an enhanced version of headways-based control method, a coordinated control method based on the self-equalizing bus headways concept involving bus holding and stop-skipping is proposed. A discrete system is formulated to describe the bus operation, and the coordinated control method is imbedded into it. In order to reflect the performance in regulating bus headways and the number of passengers, two indexes are formulated, respectively. Finally, a set of numerical analysis was conducted. The test results showed that the regulated bus headways can make the number of passengers on buses equalized. As a by-product, the headway-based control method can make the bus capacity be well utilized by equalizing bus headways on the bus route.
\end{abstract}

\section{Introduction}

If a bus on the bus line is slowed down by some disturbances, it will encounter more passengers than expected in the following bus stop and be further delayed because of longer dwell time at the bus stop. In addition, the following bus will speed up because the headway between it and the preceding bus is smaller than expected, encountering less passengers at the bus stops. The slower bus runs slower while the faster bus runs faster. Finally, buses will bunch up and cruise together. This issue was proposed by Newell and Potts [1] first, named "bus bunching." Bus bunching results in longer waiting and travel times for the passengers and the increased environment pollution due to the inefficient operation of unevenly loaded buses. In addition, the unbalanced load of passengers on successive buses wastes bus capacity, because the leading bus will be quite crowded while the trailing bus will be relatively empty; the experience of passengers on the preceding bus is quite bad. Furthermore, the bunched buses have negative effects on traffic flow at the signalized intersection causing additional car delays [2].

To handle with this intractable issue, researchers have proposed many control methods. With the advent of new technologies, some holding strategies have been proposed to take advantage of real-time information so as to reduce passengers' waiting times [3-6]. Using real-time information, many headway-based holding strategies have been proposed to adaptively control the system [7-13]. A "twoway-looking control" bus headway control method was proposed by Daganzo [14]. This method attempts to make the headways to have presettled static values. Later, Daganzo and Pilachowski [15] proposed a control strategy that continuously adjusts the bus' cruising speed on the route based on a cooperative two-way system to achieve proper spacing between the successive buses on the line. As an extension of this control concept, Xuan et al. [16] proposed a holding strategy to regularize headways while maximizing the commercial speeds, as well as considering both the 
forward and backward headways. Bartholdi and Eisenstein [8] proposed a self-adaptive control method to equalize bus headways on the bus route automatically. To integrate the advantages of the "two-way-looking control" and the "selfadaptive equalizing bus headway," Liang et al. [17] proposed a self-equalizing control strategy based on the two-waylooking control method (the headways between the bus at the control point and both its leading and following buses) with zero slack. More recently, Zhang and Lo [18] proposed two-way-looking self-equalizing headway control that considered multifarious variables, enriching the headwaybased bus holding control method system.

However, in the self-adaptive equalizing bus headway control method system, only one holding control means was used. Bus holding is based on slowing the faster leading bus and increasing the slack to balance headways, thus decreasing the average operating speed of the total bus system to resist bus bunching. In other words, it will increase the average travel time of passengers, particularly the time of onboard passengers. Therefore, other control means at the control point can be integrated with bus holding to enhance the performance of the control method based on the selfadaptive equalizing bus headway control concept.

Stop-skipping strategy may be used in which a bus is asked to skip a stop as long as nobody inside the bus requests to stop, even though there are passengers at the bus stop waiting to board the bus. Different criteria such as the operational costs, average waiting time, and passenger awareness should be considered to determine which stops should be skipped. In the early work on rail systems by Suh et al. [19], a stop-skipping strategy was utilized to increase the speed of subway service. Sun and Hickman [20] proposed a stop-skipping strategy to minimize the passenger waiting times but allowed the passengers to alight at stops in the skipped segment. A multiobjective optimization approach for stop-skipping strategies was addressed by Sidi et al. [21]. Cortés et al. [22] and Sáez et al. [23] developed a hybrid predictive control formulation that jointly estimates the bus speed, while implementing control strategies such as skipping stations or holding buses. Delgado et al. [10] addressed the combination of holding strategies with boarding limits. The authors developed a deterministic optimization model capable of executing two strategies: holding and boarding limits (limiting the amount of passengers that can board a bus even if the bus is not at full capacity; this control strategy was also used in [24]).

Based on the above-mentioned analyses, traditional control means of stop-skipping and boarding limits can both accelerate the bus at control point, while the following bus can be slowed down by leaving more passengers for it. However, in practice, it is not easy to control the extent of lined up passengers or refusing part of them to enter the vehicle even when the vehicle is not full and when the following vehicle is not yet in sight. Therefore, stop-skipping in this paper refers to the bus only providing service for alighting passengers when the control point is skipped.
On the other hand, in general, the bus fleet size problem is considered as a subproblem of Transit Network Timetabling or Vehicle Scheduling Problem instead of independent problem. Transit Network Timetabling [25-28] is to define arrival and departure times of buses at all stops along the transit network in order to achieve different goals such as meet a given frequency, satisfy specific demand patterns, maximize the number of well-timed passenger transfers, and minimize waiting times. Vehicle Scheduling Problem [2935 ] is to determine the trips-vehicles assignment to cover all the planned trips such that operational costs based on vehicle usage are minimized.

The method that integrated "two-way-looking control" with "self-adaptive equalizing bus headway" has been p6roven to perform well in reducing bus bunching and improving the service level for passengers. However, this kind of headway-based control method only focused on the regulation of bus headways without considering the number of buses on the route. The number of buses is usually assumed in advance, and the task of the control method is to regulate the headways between successive buses. The control method may fail to regulate the bus headways due to quite enough fleet size on the route, even though the control method itself is effective. Although recently this issue has been discussed for several times $[36,37]$, they mainly gave a method to equalize bus headway, without considering the capacity of bus and analyzing the impact of fleet size on the control performance. In addition, these studies made an optimal issue with fleet size and holding control. However, this work used the holding control method only instead of the coordinated stop-skipping method.

Therefore, the objective of this paper was to analyze the performance of the headway-based control method with variable fleet size considering the capacity constraint of buses. This study attempted to search the relationship of number of passengers and the bus headway, which has been merely analyzed in previous studies. In addition, this work proposed a discrete version of the coordinated control method involving bus holding control means and stopskipping control means to equalize bus headways automatically and analyzed the relationship between bus fleet size and the performance of the coordinated control method, considering the index of bus headways deviation and the deviation of number of passengers on buses.

The remainder of this paper is organized as follows. In Section 2, the coordinated control algorithm is proposed to dynamically select the two control means based on predictive control. The developed self-adaptive control method can dynamically decide which bus should dwell and its holding time or skip the control point. In Section 3, the buses' operation process has been described by formulating as a discrete system where the coordinated control method is imbedded into. The operation rules are divided into operation at the normal bus stop and at the control point. In Section 4, two performance indexes are proposed to reflect the regulation of bus operation and the condition of passengers on the buses. A set of numerical test is conducted in Section 5, using the proposed coordinated control method 
with variable fleet size under different passengers' arrival rates.

\section{Coordinated Control Strategy}

In this section, a dynamic control strategy was developed to equalize bus headways, resisting bus bunching. A dynamic selection algorithm of control means including bus holding, stop-skipping, and no control means was implemented in the proposed coordinated control method. The control variables, e.g., holding time, can be calculated by analyzing both the real-time bus running status and passenger demand. The coordinated control method proposed in this paper is derived from the control concept of self-adaptive equalizing bus headways proposed in Liang et al. [17], which is suitable to be applied to a high-frequency bus route. A selfadaptive method to equalize headways based on bus holding was tested and proved to perform well for cutting down slack time and enhancing operation efficiency of buses. However, successive bus headways at control point cannot be equalized completely using bus holding control means only, because the bus holding control means is insufficient when the forward headway is larger than the backward headway; that is, the bus holding cannot speed up the slow bus. Therefore, there is still room to develop a control method that enhances the ability to resist bus bunching while maintaining the stability of the bus system. Because studies that predict the related parameters in bus systems are relatively mature [38-42], the evolution of bus systems can be predicted with these methods in practice. In addition, the estimations of urban traffic parameters are also sufficiently mature, e.g., travel speed and queue length at signalized intersection $[43,44]$. Therefore, the main object of this section is to propose an enhanced method that combines the bus holding control means and stop-skipping control means based on the self-adaptive equalizing headways control concept.

2.1. Control Means Analysis. In the proposed coordinated control method, we integrated bus holding control means and stop-skipping control means to equalize bus headways. Bus holding control refers to the bus at control point dwelling for additional time after providing service for passengers on bus and waiting at control point. In traditional research, the stop-skipping control is a static schedule to improve operation efficiency of the bus system instead of a dynamical control means to control the bus at control point. Therefore, we use the real-time stop-skipping control strategy proposed by Sun and Hickman [20], which just allows the passengers to alight at stops in the skipped segment and only resists the passengers on control point to board. This kind of stop-skipping control method can speed up the slower bus through dwelling shorter time and meanwhile slow down the faster following bus by giving it more passengers to pick up. In addition, the passengers on the bus can alight at any bus stops, avoiding missing the destination bus stop and causing dissatisfaction of passengers.
If the bus headways are quite equalized, the bus at the control point should not be controlled with any control means. We also give this kind of condition a name, "no control means." Therefore, three control means can be used at the control point involving bus holding, stop-skipping, and no control means. The core of the coordinated control method is to dynamically select proper control means to equalize the bus headways, according to the predicted control results. The detailed control strategy and algorithm are introduced in the following section.

2.2. Control Strategy at Control Point. When a bus has just arrived at the control point, it should judge whether the stop-skipping control means is suitable to be used to equalize the bus headways. If the stop-skipping control means is selected to be used, the bus can leave the control point directly after letting the passengers alight. If the stopskipping control means is not suitable to be used, the bus can provide normal service for the passengers on the bus and wait at the control point. After the normal service, it should judge whether the bus holding control means is suitable to be used to equalize the bus headways. If the holding control means is not suitable to be used, the bus can leave the control point. Otherwise, the bus should dwell at the control point for a suitable additional time.

It should be mentioned that the stop-skipping control means should be considered when the bus has just arrived at the control point, and the bus holding should be considered after the bus providing service, because the predictive values of headways can be more accurate due to shorter prediction step length.

According to the previous research conclusion by Liang et al. [17, 37, 45], the bus headways can be convergent to a common value after continually equalizing the two bus headways between the bus at control point and its leading and following buses. Therefore, we only focus on three buses in one moment involving the bus at control point and its leading and following buses, as shown in Figure 1. We define the bus headway as the time between two successive buses leaving the same bus stop. According to this definition, the bus headway between the bus at the control point and its leading bus can be predicted after the bus at the control point leaves the current bus stop, named $\widetilde{h}_{l}$. The bus headway between the bus at the control point and its following bus can be predicted after the following bus leaves the control point, named $\widetilde{h}_{f}$. The selection of variable control means can be obtained through comparing the values of $\widetilde{h}_{l}$ and $\widetilde{h}_{f}$ under different control means.

Concretely, the control process at the control point is shown in Figure 2. When the bus has just arrived at the control point, it should judge whether the no control means should be used, firstly. According to the prediction of two successive bus headways without any control means, the values of $\widetilde{h}_{f}^{\text {no }}$ and $\widetilde{h}_{l}^{\text {no }}$ can be obtained. If the following bus headway is larger than the leading bus headway, it means that the bus at the control point at the current moment runs faster than expected and the stop-skipping control point cannot be used. The bus can provide service for the 

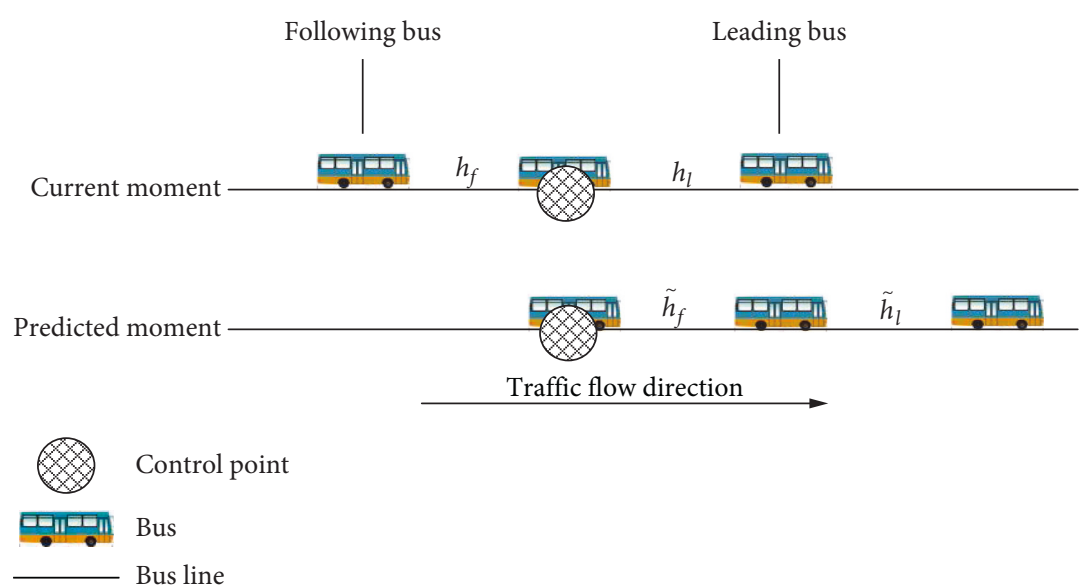

Figure 1: Prediction of step length in the coordinated control method.

passengers waiting at the control point. On the contrary, if the $\widetilde{h}_{f}^{\text {no }}$ is smaller than $\widetilde{h}_{l}^{\text {no }}$, it means the bus at the control point at the current moment runs slower than expected. However, the stop-skipping control means cannot be used arbitrarily, because the stop-skipping control means is a strong strategy to change the bus headways. It can speed up the leading bus while slow down the following bus. Therefore, it may cause hypercorrection when the $\widetilde{h}_{f}^{\text {no }}$ is only a little smaller than $\widetilde{h}_{l}^{\text {no }}$. In order to avoid this issue, the two bus headways should be predicted under stop-skipping control means, which are $\tilde{h}_{f}^{\text {ss }}$ and $\widetilde{h}_{l}^{\text {ss }}$. Because the no control means and stop-skipping control means cannot make the two bus headways equalized completely, the difference between $\left|\widetilde{h}_{f}^{\text {no }}-\widetilde{h}_{l}^{\text {no }}\right|$ and $\left|\tilde{h}_{f}^{\text {ss }}-\tilde{h}_{l}^{\text {ss }}\right|$ should be compared. If the $\left|\widetilde{h}_{f}^{\text {no }}-\widetilde{h}_{l}^{\text {no }}\right|$ is smaller than $\left|\widetilde{h}_{f}^{\text {ss }}-\widetilde{h}_{l}^{\text {ss }}\right|$, it means that the stopskipping control means changed the bus headways too much, not suitable to be used for the bus at the control point at the current moment. On the contrary, the stop-skipping control means should be used to obtain more equalized bus headways, and the bus can leave the control point after providing service for the alighting passengers. Although these two control means cannot equalize the two successive bus headways completely, it can make the headways tend to be equalized as far as possible, according to this principle mentioned above.

If the stop-skipping control means is not suitable to be used for the bus at control point, the bus can provide service for both alighting and boarding passengers. After finishing the service for passengers, the bus at the control point should consider using bus holding control means or no control means. It should be mentioned that the two headways $\widetilde{h}_{f}^{\text {hc }}$ and $\widetilde{h}_{l}$ under bus holding are predicted after providing service for both alighting and boarding passengers instead of predicted when the bus has just arrived at the control point, because it can shorten the predictive time length improving prediction accuracy in practice. The bus holding control means is different from the no control means and stopskipping control means, because the latter two control means is a kind of "yes or no" control strategy, and the bus holding control means should give specific additional holding time. In this paper, we design a discrete system to describe the bus operation process. Therefore, the predicted values of $\tilde{h}_{f}^{\text {hc }}$ and $\tilde{h}_{l}^{\text {hc }}$ can be obtained through dwelling more $\Delta t$, and if the $\tilde{h}_{f}^{\mathrm{hc}}$ is still larger than $\tilde{h}_{l}^{\mathrm{hc}}$, dwell another $\Delta t$ then. The bus cannot leave the control point until the $\tilde{h}_{f}^{\text {hc }}$ is no larger than $\widetilde{h}_{l}^{\text {hc }}$. During the dwelling period, the new arrived passengers can get on the bus.

According to the dynamic control means selection procedure shown in Figure 2, the bus at the control point can make proper decision to equalize the two successive bus headways. The bus headways on the bus route can be regulated by continually equalizing the successive bus headways.

\section{Bus Operation Process under Different Control Scenarios}

In this section, a discrete system of bus operation process is proposed where the coordinated control method proposed in Section 2 is imbedded into. On a bus line, the bus always runs on the road between two successive bus stops or dwells at the bus stop to provide service to the passengers. The bus stop can be classified into normal bus stop and control point. At the normal bus stop, the bus cannot leave until finishing the service for both passengers on the bus and at the bus stop. At the control point, the bus should be controlled by the coordinated control method proposed in Section 2. The discrete operation process of buses can be designed as follows.

3.1. Bus Operation at Normal Bus Stops. A discrete system is designed to describe the operation of buses. The running time is divided into a serious of uniform short time intervals $\Delta t$, e.g., 1 second.

A bus can move forward between two successive bus stops with distance $\Delta t \cdot v(t)$, for which we assume that the velocity $v(t)$ of the bus is constant during short time interval 


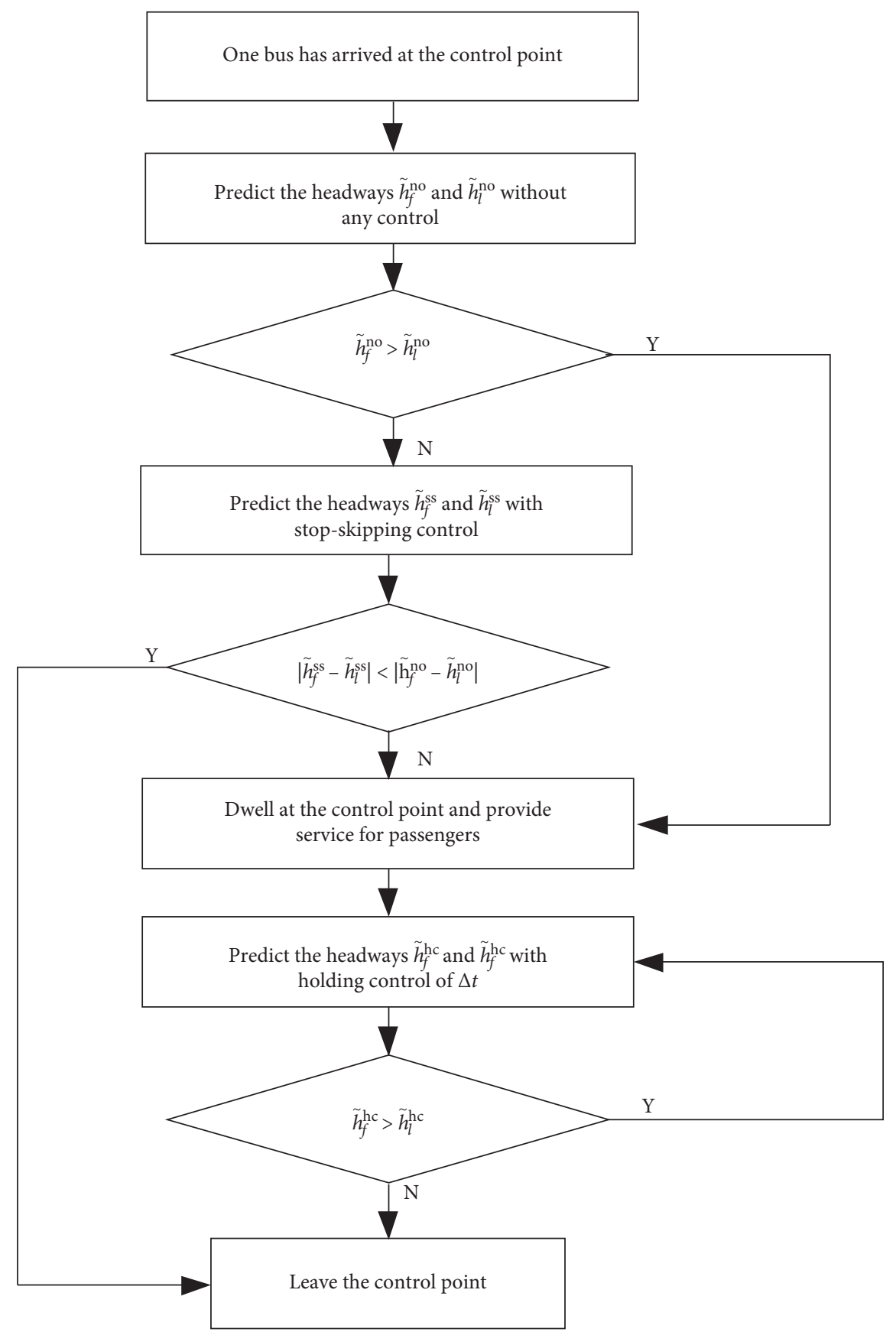

FIgURE 2: Principal control strategy procedure for bus operation at the control point.

from $t$ to $t+\Delta t$. Therefore, the location $l_{n}(t+\Delta t)$ of bus $n$ at time $t+\Delta t$ on the bus line between two successive bus stops can be shown as

$$
l_{n}(t+\Delta t)=l_{n}(t)+\Delta t \cdot v(t) .
$$

If a bus $n$ encounters the bus stop $s$, the passengers on the bus stop begin to board on the bus $n$. The criteria of a bus $n$ encountering the bus stop $s$, whose location is expressed by $l_{s}$, can be written as

$$
l_{n}(t+\Delta t)-l_{s} \in[0, \Delta t \cdot v(t)) .
$$

It is assumed that the boarding time of one passenger is constant, expressed by $\alpha$, and the alighting time of one passenger is constant as well, expressed by $\beta$. Therefore, the dwell time of one bus at normal bus stop for providing service to passengers can be written as

$$
t_{d}=\max \left(\alpha \cdot P_{b}, \beta \cdot P_{a}\right),
$$

where $P_{b}$ and $P_{a}$ refer to the number of boarding and alighting passengers, respectively.

In the discrete system, the $P_{n}(t)$ represents the number of passengers on the bus $n$ at time $t ; W_{s}(t)$ refers to the 
number of passengers waiting at the bus stop $s$ at time $t$; $A_{s}(t)$ means the number of newly arrived passengers during the period from $t$ to $t+\Delta t$. In one time interval $\Delta t$, the process of alighting and boarding can be expressed by

$$
\left\{\begin{array}{l}
P_{n}(t+\Delta t)=P_{n}(t)+\frac{\Delta t}{\alpha}-\frac{\Delta t}{\beta}, \\
W_{s}(t+\Delta t)=W_{s}(t)+A_{s}(t)-\frac{\Delta t}{\alpha} .
\end{array}\right.
$$

In fact, equation (4) only gives description of alighting and boarding process without considering the capacity limit of the bus. If the bus capacity $C$ is considered, equation (4) only suitable to be used when the $P_{n}(t)+(\Delta t / \alpha)-(\Delta t / \beta)$ is not larger than the $C$. Otherwise, the passengers cannot board because of capacity limit, although there are passengers on the bus stop $s$. Therefore, the passengers at the bus stop cannot board on bus $n$. The alighting and boarding process for passengers can be expressed by

$$
\left\{\begin{array}{l}
P_{n}(t+\Delta t)=P_{n}(t)-\frac{\Delta t}{\beta}, \\
W_{s}(t+\Delta t)=W_{s}(t)+A_{s}(t) .
\end{array}\right.
$$

If the total number of alighting passengers $\sum \Delta t / \beta$ is equal to $P_{a}$, the part $\Delta t / \beta$ in line one of equations (4) and (5) should be deleted.

The bus $n$ cannot leave the bus stop $s$ until it meets either one of the following two constraint conditions:

$$
\left\{\begin{array}{l}
W_{s}(t)=0, \sum \frac{\Delta t}{\beta}=P_{b}, \\
P_{n}(t)=C, \sum \frac{\Delta t}{\beta}=P_{b} .
\end{array}\right.
$$

3.2. Bus Operation at Control Points. If the encountered bus stop is a control point, the coordinated control method should be activated to equalize the bus headways. According to the control procedure proposed in Section 2, if the bus has just arrived at the control point, the successive bus headway should be predicted without any control means and with stop-skipping control means, respectively. If the predicted following bus headway $\widetilde{h}_{f}^{\text {no }}$ is smaller than the leading bus headway $\widetilde{h}_{l}^{\text {no }}$, it is obvious that the bus holding control means is not suitable to be used. Therefore, we should consider no control means and stop-skipping control means by comparing the difference between $\left|\widetilde{h}_{f}^{\text {no }}-\widetilde{h}_{l}^{\text {no }}\right|$ and $\left|\widetilde{h}_{f}^{\mathrm{ss}}-\widetilde{h}_{l}^{\mathrm{ss}}\right|$. If the value of $\left|\widetilde{h}_{f}^{\mathrm{ss}}-\widetilde{h}_{l}^{\mathrm{ss}}\right|$ is larger than $\left|\widetilde{h}_{f}^{\mathrm{no}}-\widetilde{h}_{l}^{\mathrm{no}}\right|$, the no control means should be used; the process can be described by using equations (4)-(6). Otherwise, the stopskipping control means should be used, i.e., the bus should leave the control point at once after providing service for the alighting passengers. The process of alighting and boarding can be expressed by

$$
\left\{\begin{array}{l}
P_{n}(t+\Delta t)=P_{n}(t)-\frac{\Delta t}{\beta} \\
W_{s}(t+\Delta t)=W_{s}(t)+A_{s}(t) .
\end{array}\right.
$$

The bus can leave the control point when all the passengers wanting to alight at the bus stop $s$ have finished, which can be written as

$$
\sum \frac{\Delta t}{\beta}=P_{b} .
$$

If the stop-skipping control means is abandoned because $\left|\widetilde{h}_{f}^{\mathrm{ss}}-\widetilde{h}_{l}^{\mathrm{ss}}\right|$ is larger than $\left|\widetilde{h}_{f}^{\text {no }}-\widetilde{h}_{l}^{\text {no }}\right|$, the bus can provide service for passengers at the control point. When the bus has finished the normal service for alighting and boarding passengers, it should consider whether the bus holding control means should be used or not. As mentioned in Section 2, the passengers newly arrived at the control point can still get on the holding bus. Therefore, the boarding process and the change of passengers' number can be expressed by

$$
\left\{\begin{array}{l}
P_{n}(t+\Delta t)=P_{n}(t)+\frac{\Delta t}{\alpha}, \\
W_{s}(t+\Delta t)=W_{s}(t)+A_{s}(t)-\frac{\Delta t}{\alpha} .
\end{array}\right.
$$

The bus can leave the control point when the predicted bus headway $\widetilde{h}_{f}^{\text {hc }}$ is no larger than $\widetilde{h}_{l}^{\text {hc }}$ and all the newly arrived passengers have boarded the bus. The following condition should be met:

$$
\left\{\begin{array}{l}
W_{s}(t)=0 \\
\tilde{h}_{f}^{\mathrm{hc}} \leq \tilde{h}_{l}^{\mathrm{hc}} .
\end{array}\right.
$$

\section{Performance Index of Public Transit}

In the traditional research, the number of buses running on the bus line is assumed to be fixed or given in advance. In this section, we mainly formulate two indexes to reflect the performance of the coordinated control method under different vehicle scheduling. And the vehicle scheduling in this paper mainly refers to the number of buses running on the bus line.

4.1. Performance Index for Bus Operation Regulation. In traditional research, the standard deviation (STD) of bus headways is usually selected as the most important index to reflect the stability of the bus system. In this paper, the bus headway means the time interval between two buses leaving 
the same bus stop. Therefore, the STD of bus headways at the bus stop $s$ can be defined as

$$
\left\{\begin{array}{l}
\sigma_{s, h}=\sqrt{\frac{\sum_{i=1}^{I_{s}-1}\left(h_{i, s}-\overline{h_{s}}\right)^{2}}{I_{s}-1},} \\
\overline{h_{s}}=\frac{\sum_{i=1}^{I_{s}-1} h_{i, s}}{I_{s}-1},
\end{array}\right.
$$

where $\sigma_{s, h}$ means bus headways STD at bus stop $s ; I_{s}$ refers to the total times the bus had left the bus stop $s ; h_{i, s}$ is the headway between $i$ to $i+1$; and $\bar{h}_{s}$ is the arithmetic mean value of bus headways.

With a fixed number of buses on the bus line $N$, the bus headways STD at bus stop $s$ can be expressed by $\sigma_{s, h}(N)$. The performance index of the coordinated control method is STD of bus headways. Therefore, the earnings by adding more one bus on the bus route can be expressed by $\left|\sigma_{s, h}(N)-\sigma_{s, h}(N+1)\right|$. With increasing number of buses on the bus route, the average bus headway would be decreased. Therefore, $\sigma_{s, h}(N+1)$ would be smaller than $\sigma_{s, h}(N)$, because of smaller average bus headway. In order to partly counteract the influence of decreasing average bus headway by adding one more bus, we formulate the relative difference index to reflect the earnings. The index $P_{1, s}$ can be shown as

$$
P_{1, s}(N+1)=\frac{\left|\sigma_{s, h}(N)-\sigma_{s, h}(N+1)\right|}{\sigma_{s, h}(N)} .
$$

4.2. Performance Index for Passengers. It is well known that when two buses are bunched, the leading bus has the larger number of passengers than the following bus, causing the leading bus to be quite crowded while the following bus is relatively empty. Therefore, the passengers in the leading bus have bad experiences, and the capacity of the following bus is wasted because the number of passengers is far less than the bus capacity.

According to the analysis mentioned above, a performance index to reflect the usage rate of bus capacity should be proposed. The index can be expressed by

$$
\frac{P_{n, s}(t+\Delta t)}{C}, \quad \text { if } l_{n}(t+\Delta t)=l_{s}+\Delta t \cdot v(t) .
$$

In this index, the $P_{n, s}(t+\Delta t)$ means the number of passengers on the bus $n$, when the bus just leaves the bus stop $s$. The variable $C$ refers to the capacity of the bus.

Similarly, the STD of the number of passengers on the bus $n$ at the bus stop $s$ can be formulated as

$$
\left\{\begin{array}{l}
\sigma_{s, p}=\sqrt{\frac{\sum_{i=1}^{I_{s}}\left(P_{i, s}-\overline{P_{s}}\right)^{2}}{I_{s}}}, \\
\overline{P_{s}}=\frac{\sum_{i=1}^{I_{s}} P_{i, s}}{I_{s}},
\end{array}\right.
$$

where $\sigma_{s, p}$ means the STD of passengers on the bus when leaving the bus stop $s$; $I_{s}$ refers to the total times the bus had left the bus stop $s$; $P_{i, s}$ is the passengers on the bus when leaving the bus stop $s ; \bar{P}_{s}$ is the arithmetic mean value of passengers on the bus when the leaving bus stop $s$.

With a fixed number of buses on the bus line $N$, the STD of passengers on the bus leaving the bus stop $s$ can be expressed by $\sigma_{s, p}(N)$. Therefore, the earnings by adding more one bus on the bus route can be expressed by $\left|\sigma_{s, p}(N)-\sigma_{s, p}(N+1)\right|$. With increasing number of buses on the bus route, the average passengers on the bus would be decreased. Therefore, the $\sigma_{s, p}(N+1)$ would be smaller than $\sigma_{s, p}(N)$, because of the smaller number of passengers. In order to counteract the influence of decreasing number of passengers by adding one more bus, we formulate relative difference index to reflect the earnings. The index $P_{2, s}$ can be shown as

$$
P_{2, s}(N+1)=\frac{\left|\sigma_{s, p}(N)-\sigma_{s, p}(N+1)\right|}{\sigma_{s, p}(N)} .
$$

\section{Numerical Analysis}

In order to explore the relationship between the performance of coordinated control method and the bus fleet size on the bus route, a set of numerical tests are conducted. In Section 5.1, the input of the simulation bus line is introduced, as well as the input variables and their values. In Section 5.2, the raw test results obtained from the numerical test are shown, including the number of the passengers on the buses and the headway deviations on the bus line. The index values calculated according to the formulas from Section 4 are presented in Section 5.3, followed by analysis and discussion for the results.

5.1. Basic Data of Bus Line. The proposed coordinated control method was used for a simulated route based on Route 80 in Changchun City. The busy route circles a city of about $12 \mathrm{~km}$. We selected 15 major bus stops on this route, two of which were control points (bus stop 6 and bus stop 11). The number of buses operating on the bus route is variable changing from 8 to 14 , although in one test, the number of buses running on the bus line is fixed. We set that one passenger boarding requires two seconds, and one passenger alighting requires one second. The duration time of one simulation was $4 \mathrm{~h}$. To evaluate the performance of the proposed control method under different traffic demands, the total variable demand sets of the bus route are listed in Table 1. There are three groups to be tested named $\mathrm{r} 1, \mathrm{r} 2$, and $\mathrm{r} 3$. As shown in Table 1, the demand of group r3 is the largest, while the demand of group $\mathrm{r} 1$ is the least. The arriving process and alighting proportions at each bus stop are shown in Figure 3. The demands in the table are the average values instead of constants. We use an average bus travel speed of $5 \mathrm{~m} / \mathrm{s}$ between two successive bus stops. The bus capacity was $80 \mathrm{pax} / \mathrm{veh}$. Considering the random disturbance caused by passengers, the travel speed of buses on the bus route has indeterminacy. 
TABLE 1: Arrival rate of the bus route.

\begin{tabular}{lccc}
\hline Group & r1 & r2 & r3 \\
\hline Average arrival rate $(\mathrm{pax} / \mathrm{h})$ & 1890 & 2430 & 2970 \\
\hline
\end{tabular}

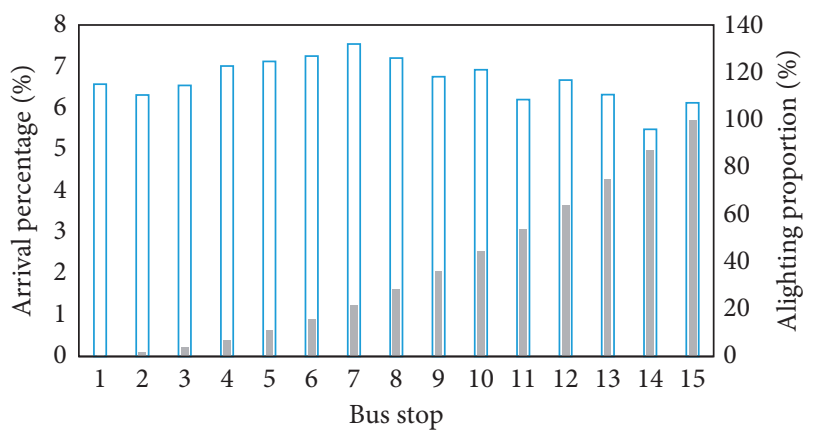

$\square$ Average arrival percentage

- Alighting proportions

Figure 3: Percentage of average passenger arrivals and alighting at each stop.

In the numerical test, the demand of passengers can be obtained by Table 1 and Figure 3. More exactly, for example, at the bus stop 6 , the boarding passengers during unit time can be calculated by $1890 \mathrm{pax} / \mathrm{h}$ (shown in Table 1) multiplyied by arrival percentage 7.1\% (shown in Figure 3). We assumed that the passenger arrivals follow a Poisson distribution. The arrival process in each $\Delta t$ of passengers can be described with the aid of Matlab's "poissrnd" function. Therefore, the number of passengers arrived bus stop 6 at each time $\Delta t$ can be obtained. In addition, the alighting demand is relatively simple, which is the number of passengers on buses multiplied by alighting proportion at each bus stop shown in Figure 3. Therefore, in this paper, in the model, the demand of passengers is assumed to be known in advance, and in the numerical test, the demand calculation process has been shown above.

Since the arrival process is stochastic, special cases may occur: these could either be no passenger or many passengers reaching the bus stop during a period and both cases may affect the results greatly. According to the Monte Carlo method, repeating the tests for enough times can obtain a more general conclusion. Therefore, to eliminate effects of random factors, the program was run 100 times to generate passenger arrival processes at bus stops. We built a simulation platform based on the running process of buses described in Section 3, imbedding the control method into. Thus, 100 groups of results were obtained.

The data of the bus line are introduced into the simulation platform, and the test results can be obtained. In one test, the average passengers' demand and the number of buses on the bus route are fixed. In order to obtain a more general result, for a fixed average passengers' demand and a fixed number of buses on the bus route, the test should be conducted 100 times. As shown in Figure 4, the $x$-axis is the repeated times, while the blue line represents travel time and the orange line means relative difference, respectively.
According to Figure 4, along with the increasing simulation times, the average values of travel time tend to be stable just a little smaller than 5,830,000 s after 100 repeated times. More exactly, the relative difference of the average value with its front one becomes smaller along with increasing repeated times, which is less than $0.01 \%$ after 100 repeated times. Therefore, the 100-time simulation is enough to represent a general result of public transit.

The raw test result and performance indexes are shown in Sections 5.2 and 5.3, respectively.

\subsection{Performance of the Coordinated Control Method under} Variable Bus Fleet Size. In this section, the performance of the proposed control method is presented including the STD of headways, average number of passengers, and STD of passengers on the buses. Firstly, a test result of passengers' number distribution based on groups $\mathrm{r} 1, \mathrm{r} 2$, and $\mathrm{r} 3$ with 10 buses on the bus route is presented in Figure 4. Secondly, more general results based on 100-time tests are presented involving the relationship between fleet size and bus headways and the number of passengers on the buses at each bus stop.

5.2.1. Preliminary Impression. In this section, the bus' spatiotemporal trajectory is presented first, with passengers' demand of $\mathrm{r} 2$. The $x$-axis refers to the time, and the $y$-axis means the bus position on the bus route. In addition, the distance between two bus stops is $800 \mathrm{~m}$, and the two control points locate at $4000 \mathrm{~m}$ and $8000 \mathrm{~m}$, respectively. Figures $5(\mathrm{a})-5(\mathrm{c})$ refer to 8,11 , and 14 buses on the bus route, respectively. As shown in Figure 5(a), the bus bunching did not occur because of large bus headways between successive buses. However, the holding time is relative large, which means the efficiency of the public transit is relatively low. Figure 5(c) shows that the holding time is relatively low and the trajectory of buses is smooth. However, because the bus headways are quite small, the bus bunching occurred several times after 10,000 s in the simulation test. Compared with Figures 5(a) and 5(c), Figure 5(b) shows that the trajectory of buses is relative smooth and the bus bunching does not occur because of relatively suitable bus headways and suitable fleet size.

As shown in Figure 6, the $x$-axis is the bus stop and the $y$ axis refers to the number of passengers on the bus when the bus has finished the service and just left the bus stop. In the test, there are ten buses on the bus route. Figure 6(a) shows the number of passengers on the buses at each bus stop with group r1, while Figures 6(b) and 6(c) show larger demand of group $\mathrm{r} 2$ and group $\mathrm{r} 3$. According to the first two boxplots, it is obvious that the number of passengers on the bus at bus stops $4,5,6,7$, and 8 is larger than it is at the other bus stops. And the change ranges of passengers on the bus at these five bus stops are larger than those at other bus stops. Comparing Figure 6(a) with Figures 6(b) and 6(c), the largest number of passengers on the bus in group $\mathrm{r} 1$ is still smaller than the bus capacity of 80 pax, while the number of passengers at bus stops 5 and 6 in groups $\mathrm{r} 2$ and $\mathrm{r} 3$ has been limited by the capacity of the bus. Especially, as shown in Figure 6(c), 


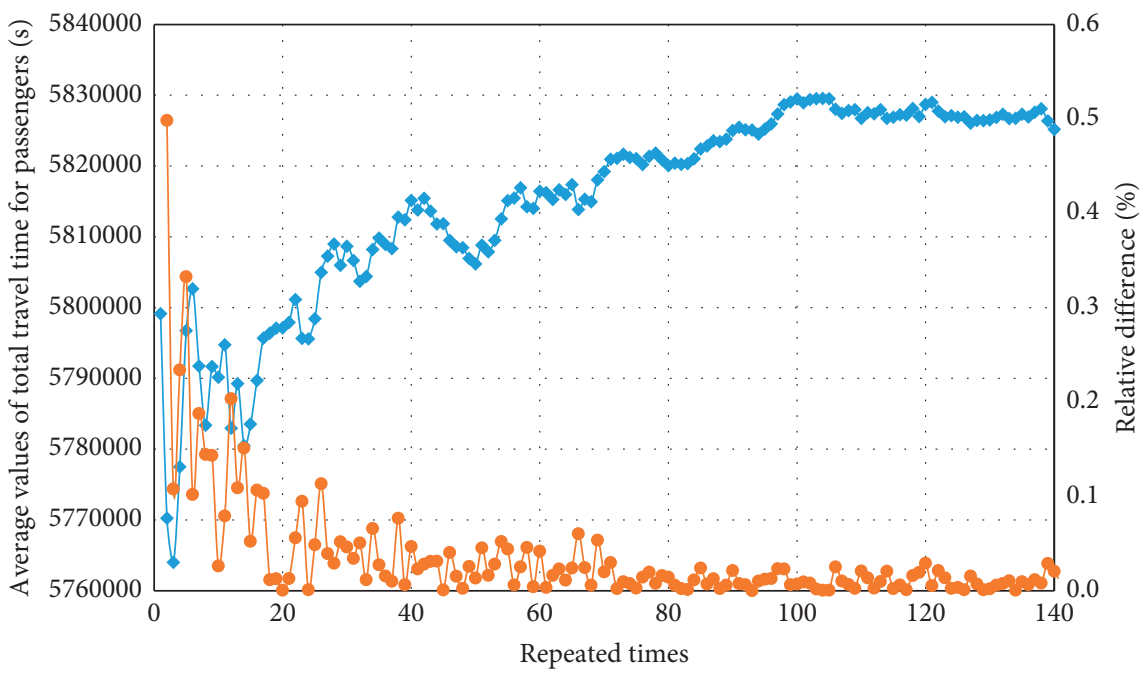

$\rightarrow-$ Average values of travel time (s)

$\rightarrow$ Relative difference

FIgURE 4: Convergent tendency with increasing simulation times.

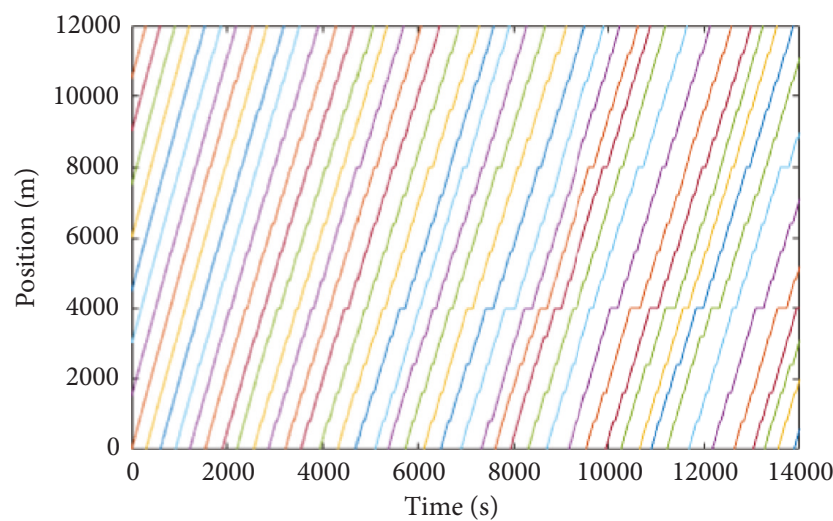

(a)

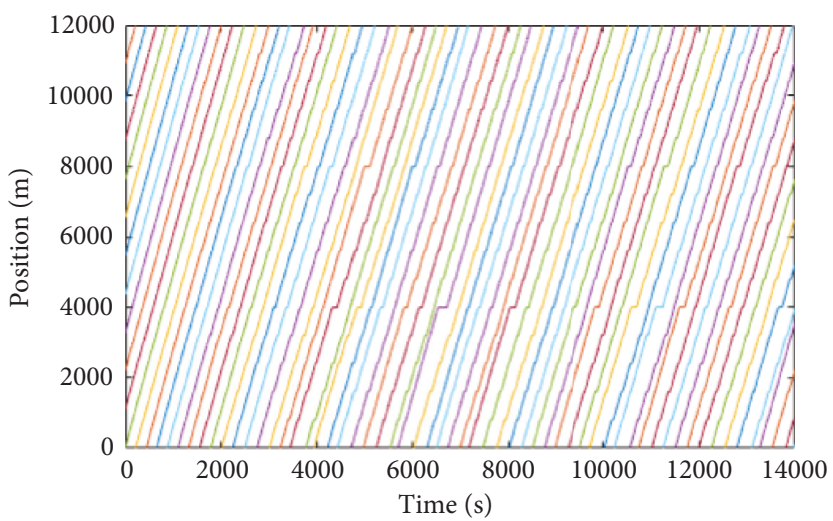

(b)

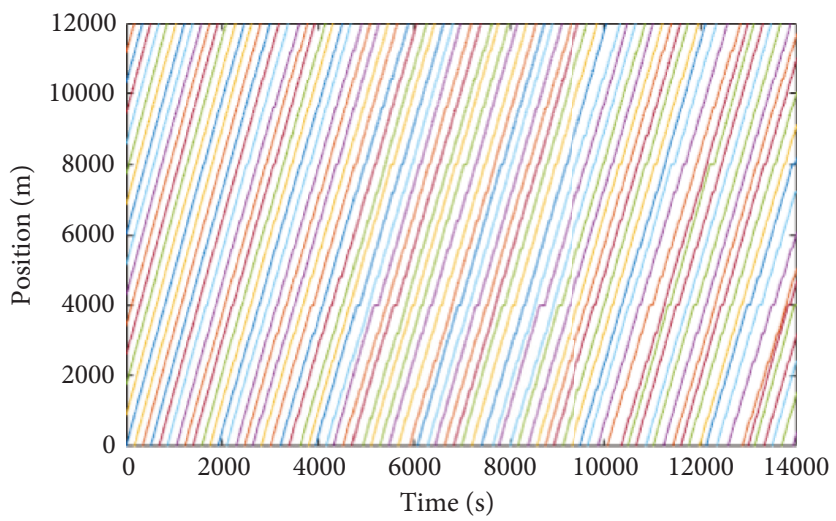

(c)

FiguRE 5: Spatiotemporal trajectory of buses. (a) With 8 buses on the bus route. (b) With 11 buses on the bus route. (c) With 14 buses on the bus route. 


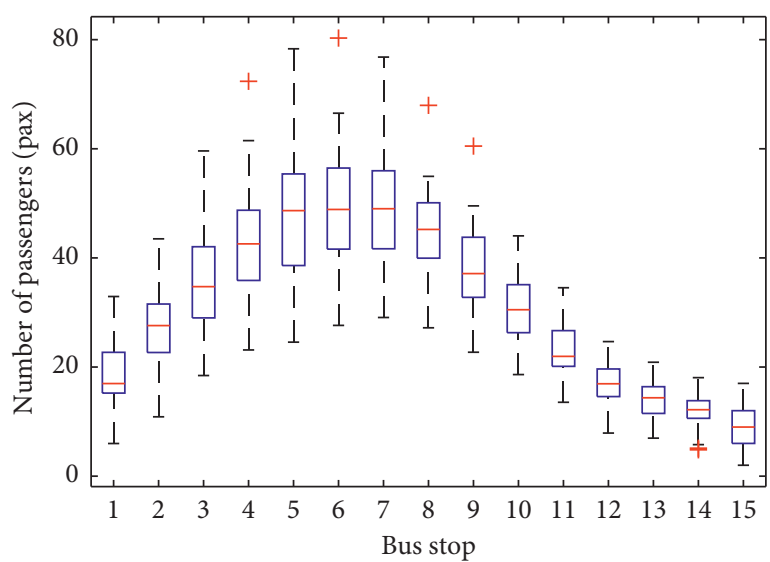

(a)

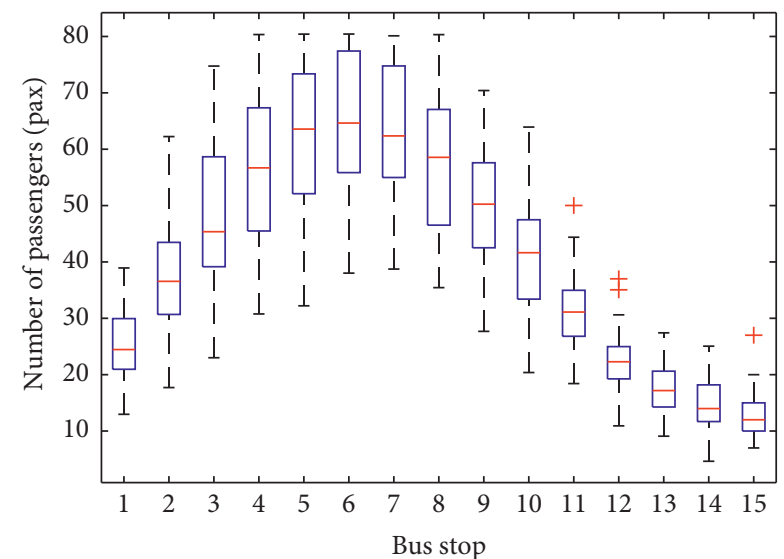

(b)

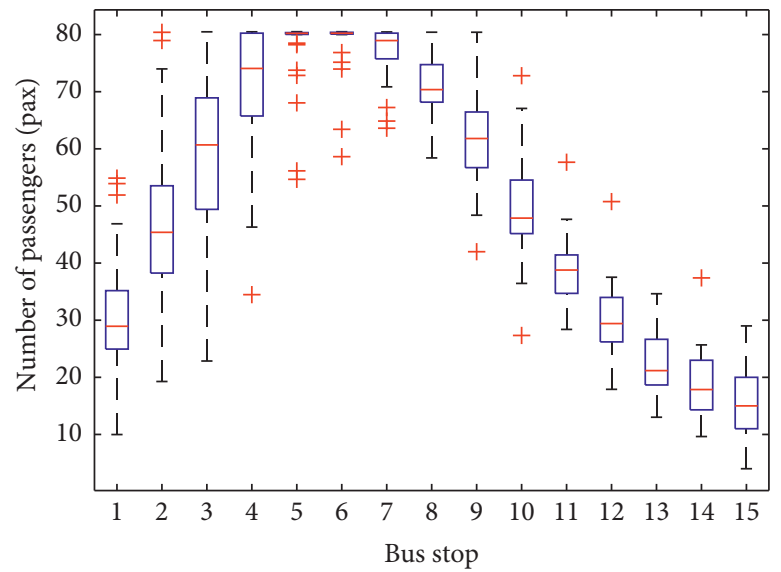

(c)

FIGURE 6: Distribution of number of passengers on buses at each bus stop. (a) Group r1. (b) Group r2. (c) Group r3.

almost all the buses are fully loaded at the bus stop 5 and bus stop 6, without extra room for more passengers.

\subsubsection{General Test Results of Bus Headways and Number of} Passengers on Buses. Figure 6 only shows the result of passengers' number distribution on buses at each stop. To obtain more general test results, 100-time tests were conducted to output the bus headways and number of passengers on buses. In this section, the test results are divided into two parts, including the bus headways changing and number of passengers changing along with the increasing number of buses.

The average bus headways are shown in Figure 7, and the STD of bus headways are shown in Figure 8. In these two figures, the $x$-axis is the number of buses on the route. The three lines refer to different arrival rates of groups $r 1, r 2$, and $r 3$.

According to Figures 7 and 8, both bus headways and STD of buses headways decrease along with increasing buses on the route. According to Figure 7, the average bus headways with a smaller arrival rate of $\mathrm{r} 1$ is smaller than those with a larger arrival rate of $r 3$. Figure 8 illustrates that the STD of bus headways decreases from $80 \mathrm{~s}$ to $60 \mathrm{~s}$ of group $\mathrm{r} 1$ while the change range is about 10 for group $\mathrm{r} 3$. Therefore, the STD of bus headways is more sensitive with the number

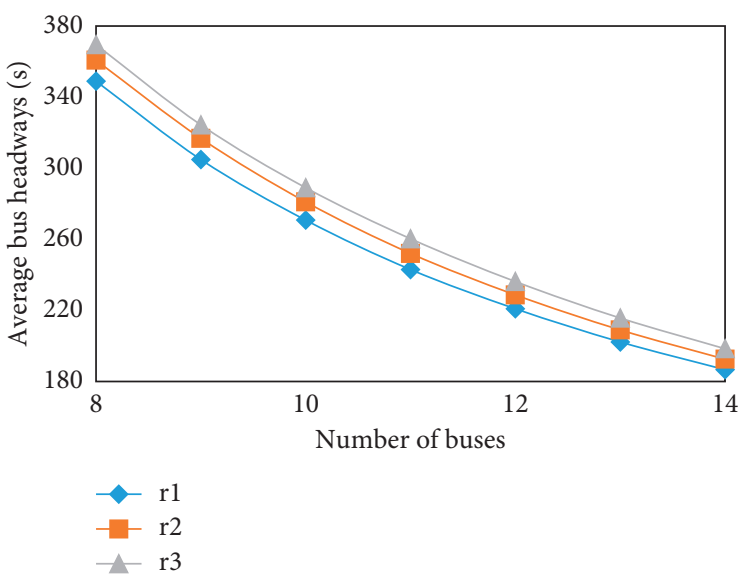

FIgURE 7: Average bus headways with increasing buses on the route.

of buses on route when the average arrival rate is large. The passengers on the buses when the buses just finished service and left the bus stops are shown in Figure 9.

In Figure 9, the $x$-axis refers to the bus stops from 1 to 15 , because there are 15 bus stops on the bus route. The $y$-axis means the number of passengers on the bus. There are seven 


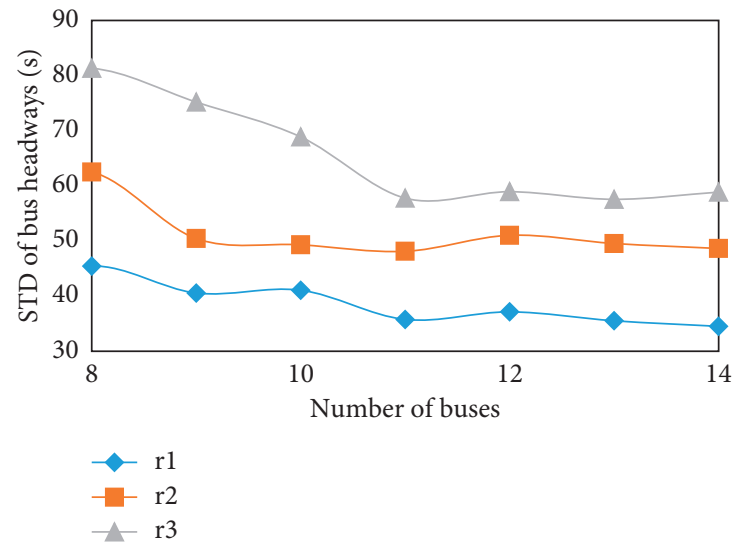

FIGURE 8: STD of bus headways with increasing buses on the route.
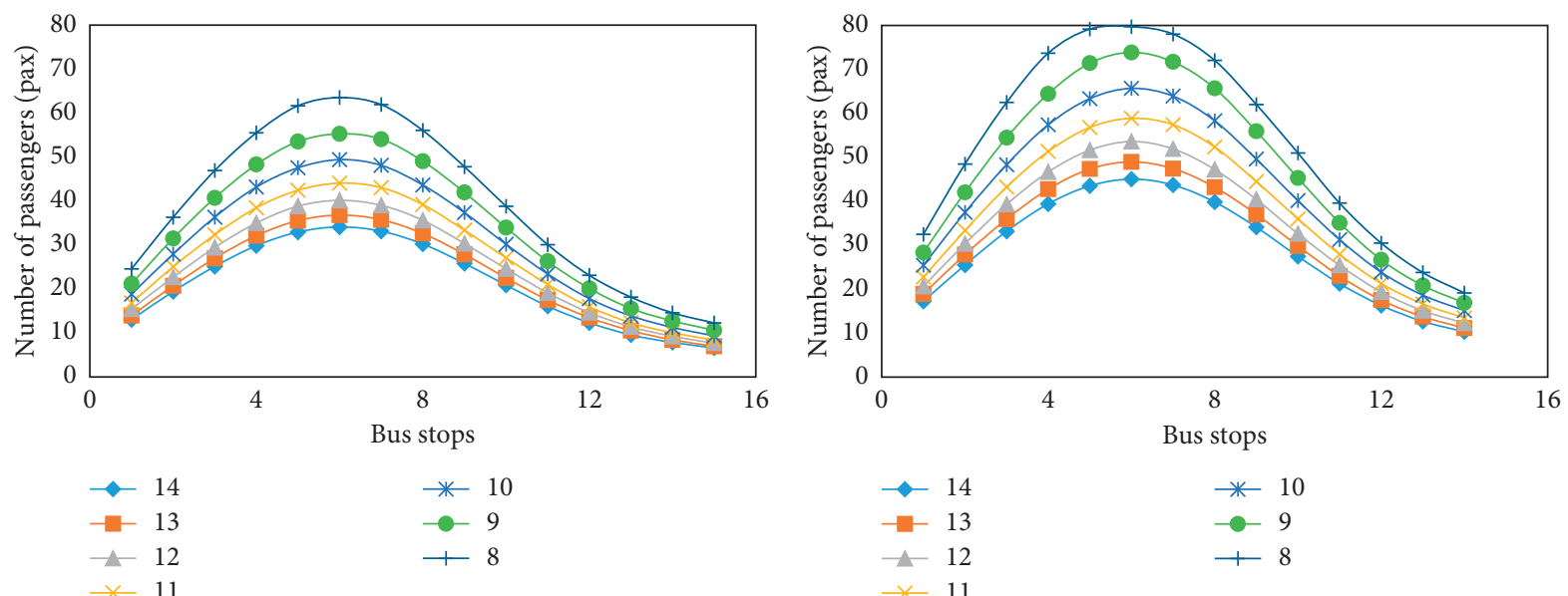

(a)

(b)

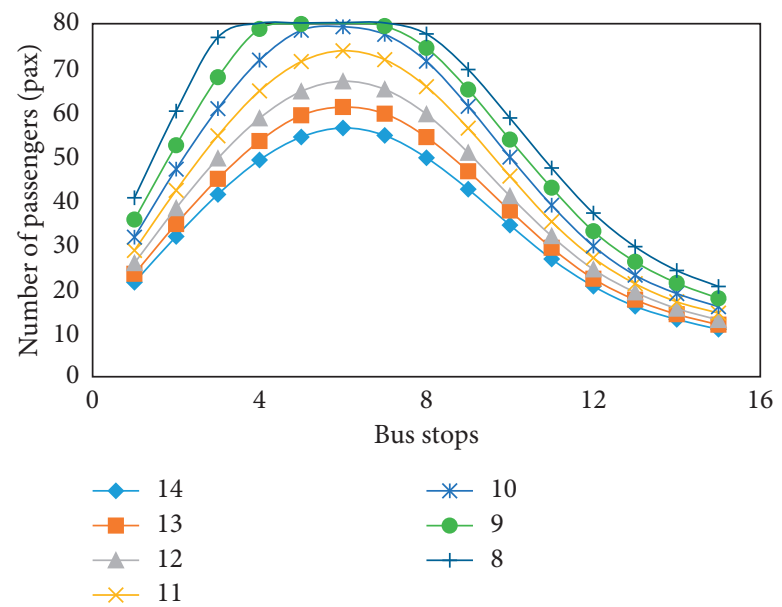

(c)

Figure 9: Number of passengers on buses at each bus stop. (a) Group r1. (b) Group r2. (c) Group r3.

lines in the figure representing the different number of buses on the route. According to Figure 9(a), the passengers on the buses are larger at bus stops from 4 to 8 than at bus stops from 11 to 15 . However, the number of passengers does not reach the capacity of bus. In Figure 9(b), the passengers on the bus have reached the capacity of bus at bus stop 6 when there are only 8 buses on the bus route. In the group $\mathrm{r} 3$, as shown in the Figure 9(c), the passengers have reached the capacity when there are 10 buses on the route. Therefore, as shown in Figure 9, the analysis for STD of passengers on the 

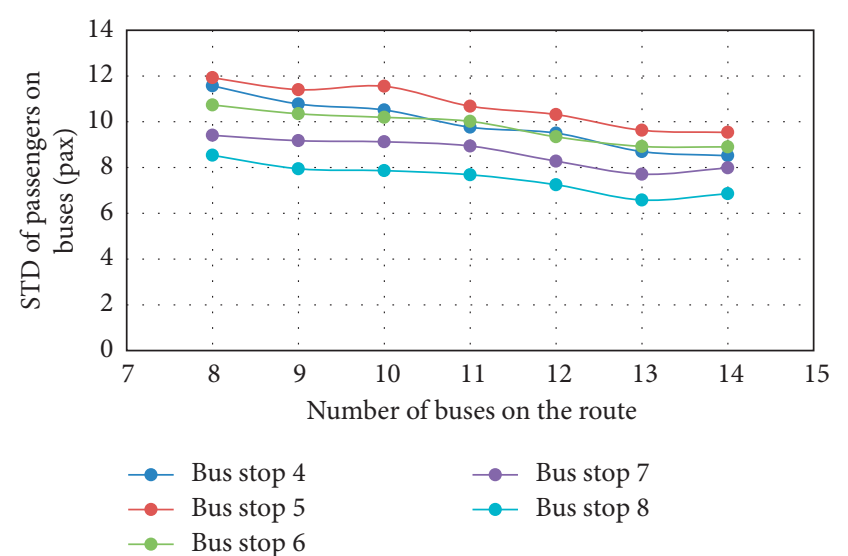

$$
\longrightarrow \text { Bus stop } 7
$$$$
\text { Bus stop } 8
$$

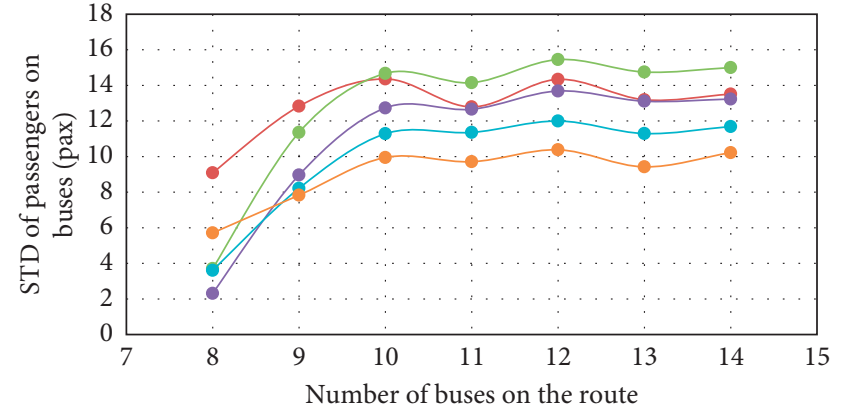

$\longrightarrow$ Bus stop 4
$\longrightarrow$ Bus stop 5

- Bus stop 6

(a)

(b)

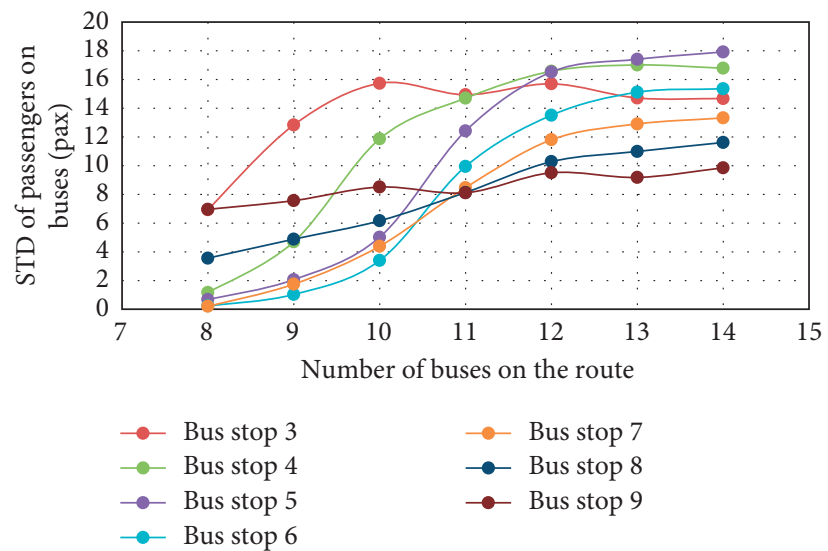

(c)

FIGURE 10: STD of passengers on buses at bus stops located at the busy section of the bus route. (a) Group r1. (b) Group r2. (c) Group r3.

buses should be divided into two parts according to the bus stops, including the passengers on the buses at bus stops located at the busy section of the bus route and the relatively empty section of the bus route.

The STDs of passengers on buses are shown in Figures 10 and 11 . Figure 10 presents the STD of passengers on buses at bus stops located at the busy section of bus route, while Figure 11 presents the STD of passengers on buses at bus stops at the other section of the bus route. The $x$-axis refers to the number of buses on the route, and the $y$-axis means the STD of passengers on buses. The lines in the figures depict the passengers at different bus stops.

As shown in Figure 10(a), the STD of passengers in group $r 1$ decreases along with the increasing number of buses on the route. This is partly because the average number of passengers on the buses decreased along with the increasing buses. Figures 10(b) and 10(c) show the STD of passengers on buses under the larger arrival rate. According to Figures 9(b) and 9(c), the passengers, who would like to get on the bus, may be limited by the bus capacity when the fleet size is relatively small. Therefore, along with the increasing number of buses on the bus route, the STD of passengers on buses increased greatly at the beginning and then decreased a little when the number of buses on the route is relatively large. This is because the number of passengers on the buses is approximately equal to the capacity of the bus when the arrival rate is relatively large and the number of buses on the route is relatively small. Therefore, the STD of passengers is relatively small at the beginning. However, when the number of buses is large, the passengers on the buses are not limited by the bus capacity. Therefore, the STD of passengers on buses decreases again with the increasing buses on the route, similar to the reason of group $\mathrm{r} 1$.

In Figures 11(a)-11(c), all the passengers on buses are not limited by the bus capacity. Therefore, the lines in the figure are monotonic decreasing. As mentioned above, the decrease is partly because of the smaller average number of passengers on the buses. However, the decreasing STD of passengers on buses whether comes from decreasing STD of bus headways should be further discussed. In Section 5.3, the values of indexes for bus headways and number of passengers are presented.

\subsection{Result Analysis for the Bus Headways and Passengers on} the Buses. According to the test result mentioned in Section 5.2 , both STD of bus headways and STD of passengers on the buses decrease along with the increasing buses on the route. One reason is that the headways and number of passengers 


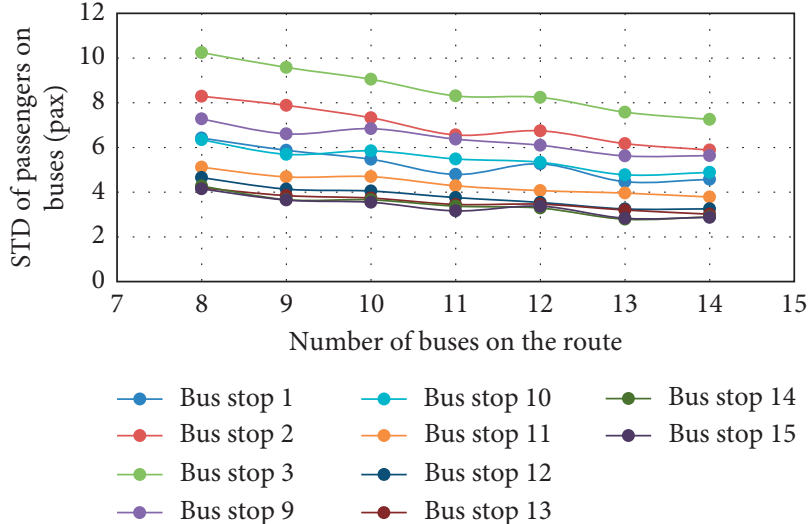

(a)

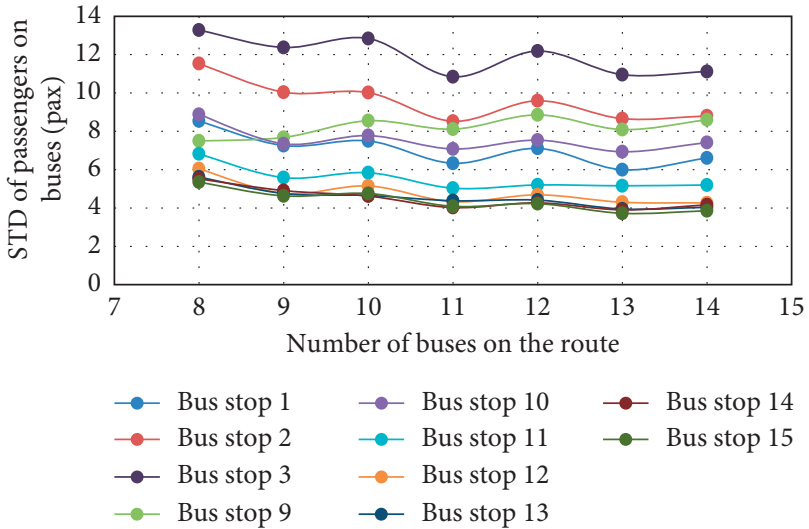

(b)

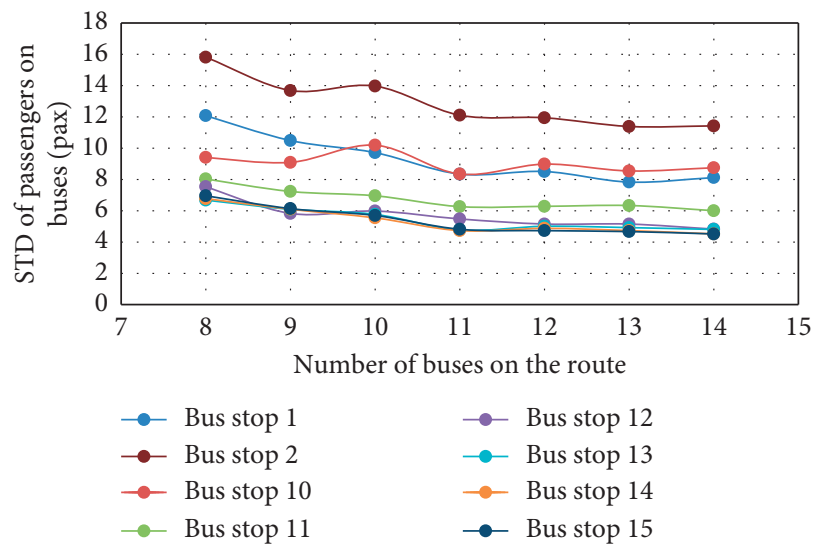

(c)

FIGURE 11: STD of passengers on buses at bus stops located at relatively empty section. (a) Group r1. (b) Group r2. (c) Group r3.

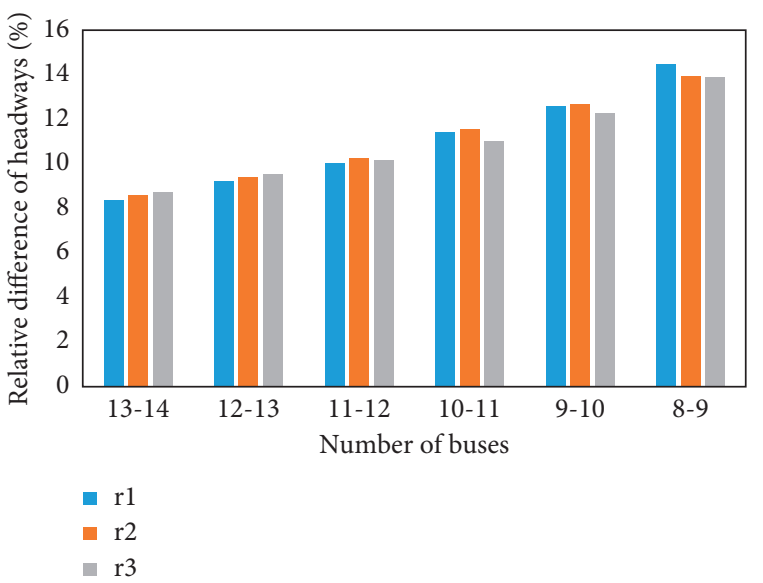

(a)

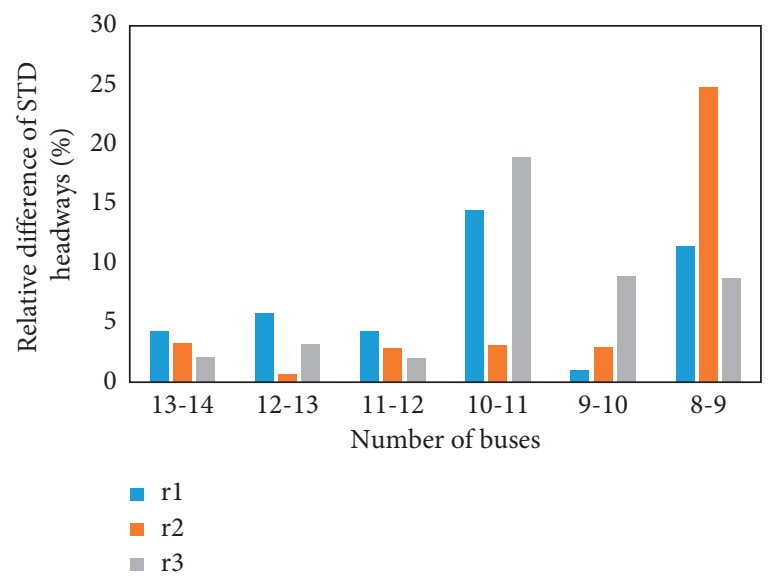

(b)

FIGURE 12: Index of bus headways along with increasing buses on the route. (a) Relative difference of headways. (b) Relative difference of STD headways.

decrease along with the increasing buses. In this section, the other reason is discussed through comparing the indexes of bus headways and number of passengers. The relationship between bus headways and number of passengers on the buses is explored. The index values calculated by equations (12) and (15) are presented in Figures 12 and 13, respectively. In Figure 12, the result analysis is divided into two parts. In Figure 12(a), the relative difference of headways adding 


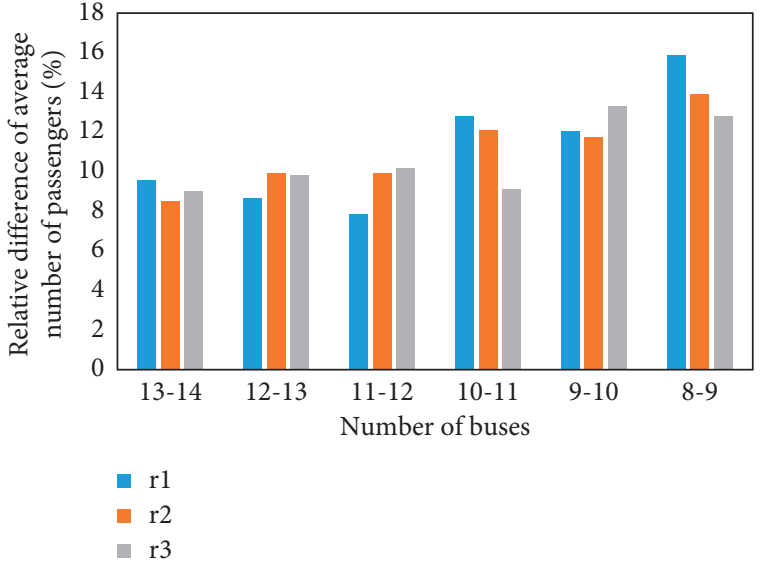

(a)

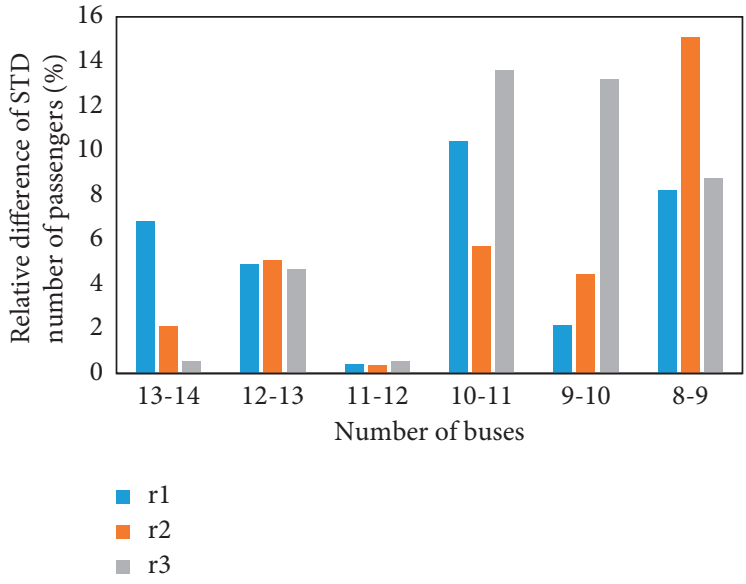

(b)

FIGURE 13: Index of passengers along with increasing buses on the route. (a) Relative difference of the average number of passengers at the busy section. (b) Relative difference of the STD number of passengers at the relatively empty section.

more one bus on the bus route is presented, while Figure 12(b) shows relative difference of STD headways adding one more bus on the route. The $x$-axis refers to the change in the number of buses on the route, and the $y$-axis means the relative difference.

According to Figure 12(a), the relative difference of bus headways decreases gradually along with the increasing bus number. It illustrates that if the number of buses on the route is relatively large, the benefit brought by adding more than one bus is relatively small. Also, similar conclusion can be obtained from Figure 12(b). The STD changes greatly when the number of buses on the route is relatively small, and when the number of buses on the route is relatively large, the change of STD of bus headways becomes small.

The other index is for the passengers on the bus. In this section, the passengers on buses at bus stops 11 to 15 are selected, because the passengers at these bus stops are not limited by bus capacity. The index values are shown in Figure 13.

The $x$-axis refers to the change of buses on the route, and the $y$-axis means benefits brought by adding one more bus. According to Figure 13(a), the relative difference of the average number of passengers increases along with the increasing number of buses. Similar conclusion can be obtained in Figure 13(b); the relative difference of the STD number of passengers changes little when the number of buses on the route is relatively large.

Comparing Figure 12(b) with Figure 13(b), it can be figured out that the variation trend in these two figures is quite similar. Therefore, the second reason for decrease of STD of passengers on buses can be obtained. This is because more equalized bus headways lead to more equalized number of bus headways. The coordinated control method can regulate the bus headways. Furthermore, the regulated bus headways can make the number of passengers in each bus equalized. Therefore, the regulated bus operation can take full advantage of the capacity of buses, because the difference of numbers on the successive bunching buses can be effectively eliminated.

\section{Conclusion}

In this paper, the coordinated bus headway control method is designed based on the adaptive self-equalized concept. Furthermore, a procedure is designed to select the bus that should be skipping or held as well as its corresponding holding time. The discrete operation system is formulated imbedding the coordinated control method and considers the limitation of the bus capacity. However, the coordinated control method is not the core contribution of this paper. The main work of this paper is to explore the relationship between the number of buses on the bus route and the performance of public transit under the control method. Furthermore, the relationship between the STD of bus headways and number of buses is obtained and discussed. It is widely acknowledged that the self-equalized bus headway control method is to regulate the bus headways and eliminate bus bunching. The STD of bus headways can reflect this performance of the public transit. Therefore, the first index is formulated based on the STD of bus headways. In addition, in order to eliminate the influence of change from the average bus headway, the relative difference of STD bus headways is formulated as the performance index for bus headways. In order to further reflect the passengers comfort on buses, the second index for passengers is formulated based on the number of passengers on buses when the bus has finished service and just left the bus stop. Similarly, along with increasing number of buses on the route, the average number of passengers on buses will be smaller. In order to eliminate the influence by the average number of passengers on buses, the relative difference of STD of passengers is selected as the index to reflect the condition of passengers.

In the section of numerical analysis, a set of numerical tests is conducted under three different arrival rates named as groups r1, r2, and r3. According to the analysis, several conclusions can be obtained: (a) The relative difference of bus headways decreases gradually along with the increasing bus number. It illustrates that if the number of buses on the 
route is relatively large, the benefit brought by adding more than one bus tends to converge. (b) The STD of bus headway changes is more sensitive with the number of buses on the route when the average arrival rate of passengers is larger. (c) The regulated bus headways can make the number of passengers in each bus equalized. As a by-product, the headwaybased control method can make the bus capacity be fully utilized by equalizing bus headways on the bus route.

This work can provide the evidence of necessity and feasibility to formulate the bus fleet size and coordinated control method into an optimization issue. Therefore, in this paper, we mainly analyze the sensitivity of the fleet size for dynamic headway-based control method performance. In the future work, we will conduct the comparison of the coordinated control method and the holding control performance in optimizing the fleet size and experience of passengers.

\section{Data Availability}

The data used to support the findings of this study are available from the corresponding author upon request.

\section{Conflicts of Interest}

The authors confirm that there are no conflicts of interest regarding the publication of this manuscript.

\section{Acknowledgments}

This work was supported by the National Natural Science Foundation of China (Grant nos. 71801149 and 71801153), Natural Science Foundation of Shanghai (Grant no. 18ZR1426200), and Technical Service Platform for Vibration and Noise Testing and Control of New Energy Vehicles (Grant no. 18DZ2295900).

\section{References}

[1] G. F. Newell and R. B. Potts, "Maintaining a bus schedule," in Proceedings of the Second Conference Australian Road Research Board, Melbourne, Australia, 1964.

[2] S. Liang and M. Ma, "Analysis of bus bunching impact on car delays at signalized intersections," KSCE Journal of Civil Engineering, vol. 23, no. 2, pp. 833-843, 2019.

[3] M. Dessouky, R. Hall, A. Nowroozi, and K. Mourikas, "Bus dispatching at timed transfer transit stations using bus tracking technology," Transportation Research Part C: Emerging Technologies, vol. 7, no. 4, pp. 187-208, 1999.

[4] X. J. Eberlein, N. H. M. Wilson, and D. Bernstein, "The holding problem with real-time information available," Transportation Science, vol. 35, no. 1, pp. 1-18, 2001.

[5] M. D. Hickman, "An analytic stochastic model for the transit vehicle holding problem," Transportation Science, vol. 35, no. 3, pp. 215-237, 2001.

[6] Y. Sun and P. Schonfeld, "Holding decisions for correlated vehicle arrivals at intermodal freight transfer terminals," Transportation Research Part B: Methodological, vol. 90, pp. 218-240, 2016.

[7] J. Argote-Cabanero, C. F. Daganzo, and J. W. Lynn, "Dynamic control of complex transit systems," Transportation Research Part B: Methodological, vol. 81, no. 1, pp. 146-160, 2015.
[8] J. J. Bartholdi III and D. D. Eisenstein, “A self-coördinating bus route to resist bus bunching," Transportation Research Part B: Methodological, vol. 46, no. 4, pp. 481-491, 2012.

[9] C. F. Daganzo, "A cheap and resilient way to eliminate bus bunching," in Proceedings of the 4th International Conference on Future Urban Transport, Gothenburg, Sweden, April 2009.

[10] F. Delgado, J. C. Munoz, and R. Giesen, "How much can holding and/or limiting boarding improve transit performance?," Transportation Research Part B: Methodological, vol. 46, no. 9, pp. 1202-1217, 2012.

[11] W. Wu, R. Liu, and W. Jin, "Designing robust schedule coordination scheme for transit networks with safety control margins," Transportation Research Part B: Methodological, vol. 93, pp. 495-519, 2016.

[12] W. Wu, R. Liu, and W. Jin, "Modelling bus bunching and holding control with vehicle overtaking and distributed passenger boarding behaviour," Transportation Research Part B: Methodological, vol. 104, pp. 175-197, 2017.

[13] W. Wu, R. Liu, and W. Jin, "Integrating bus holding control strategies and schedule recovery: simulation-based comparison and recommendation," Journal of Advanced Transportation, vol. 2018, Article ID 9407801, 13 pages, 2018.

[14] C. F. Daganzo, "A headway-based approach to eliminate bus bunching: systematic analysis and comparisons," Transportation Research Part B: Methodological, vol. 43, no. 10, pp. 913-921, 2009.

[15] C. F. Daganzo and J. Pilachowski, "Reducing bunching with bus-to-bus cooperation," Transportation Research Part B: Methodological, vol. 45, no. 1, pp. 267-277, 2011.

[16] Y. Xuan, J. Argote, and C. F. Daganzo, "Dynamic bus holding strategies for schedule reliability: optimal linear control and performance analysis," Transportation Research Part B: Methodological, vol. 45, no. 10, pp. 1831-1845, 2011.

[17] S. Liang, S. Zhao, C. Lu, and M. Ma, "A self-adaptive method to equalize headways: numerical analysis and comparison," Transportation Research Part B: Methodological, vol. 87, pp. 33-43, 2016.

[18] S. Zhang and H. K. Lo, "Two-way-looking self-equalizing headway control for bus operations," Transportation Research Part B: Methodological, vol. 110, pp. 280-301, 2018.

[19] W. Suh, K.-S. Chon, and S.-M. Rhee, "Effect of skip-stop policy on a Korean subway system," Transportation Research Record: Journal of the Transportation Research Board, vol. 1793, no. 1, pp. 33-39, 2002.

[20] A. Sun and M. Hickman, "The real-time stop-skipping problem," Journal of Intelligent Transportation Systems, vol. 9, no. 2, pp. 91-109, 2005.

[21] M. M. O. Sidi, S. Hammadi, S. Hayat, and P. Borne, "Urban transport network regulation and evaluation: a fuzzy evolutionary approach," IEEE Transactions on Systems, Man, and Cybernetics-Part A: Systems and Humans, vol. 38, no. 2, pp. 309-318, 2008.

[22] C. E. Cortés, D. Sáez, F. Milla, A. Núñez, and M. Riquelme, "Hybrid predictive control for real-time optimization of public transport systems' operations based on evolutionary multi-objective optimization," Transportation Research Part C: Emerging Technologies, vol. 18, no. 5, pp. 757-769, 2010.

[23] D. Sáez, C. E. Cortés, F. Milla, A. Núñez, A. Tirachini, and M. Riquelme, "Hybrid predictive control strategy for a public transport system with uncertain demand," Transportmetrica, vol. 8, no. 1, pp. 61-86, 2012.

[24] F. Delgado, J. C. Muñoz, R. Giesen, and A. Cipriano, "Realtime control of buses in a transit corridor based on vehicle holding and boarding limits," Transportation Research Record: 
Journal of the Transportation Research Board, vol. 2090, no. 1, pp. 59-67, 2009.

[25] S. M. M. Amiripour, A. Ceder, and A. S. Mohaymany, "Designing large-scale bus network with seasonal variations of demand," Transportation Research Part C: Emerging Technologies, vol. 48, pp. 322-338, 2014.

[26] A. Mauttone and M. E. Urquhart, "A multi-objective metaheuristic approach for the transit network design problem," Public Transport, vol. 1, no. 4, pp. 253-273, 2009.

[27] M. Medina, R. Giesen, and J. C. Muñoz, "Model for the optimal location of bus stops and its application to a public transport corridor in Santiago, Chile," Transportation Research Record: Journal of the Transportation Research Board, vol. 2352, no. 1, pp. 84-93, 2013.

[28] M. Nikolic and D. Teodorovic, "A simultaneous transit network design and frequency setting: computing with bees," Expert Systems with Applications, vol. 41, pp. 7200-7209, 2014.

[29] F. Lynn, R. Pesenti, W. Ukovich, and D. Favaretto, "A comparison of different solution approaches to the vehicle scheduling problem in a practical case," Computers \& Operations Research, vol. 27, no. 13, pp. 1249-1269, 2000.

[30] A. Ceder, "Optimal multi-vehicle type transit timetabling and vehicle scheduling," Procedia-Social and Behavioral Sciences, vol. 20, pp. 19-30, 2011.

[31] V. Guihaire and J.-K. Hao, "Transit network timetabling and vehicle assignment for regulating authorities," Computers \& Industrial Engineering, vol. 59, no. 1, pp. 16-23, 2010.

[32] O. J. Ibarra-Rojas, R. Giesen, and Y. A. Rios-Solis, "An integrated approach for timetabling and vehicle scheduling problems to analyze the trade-off between level of service and operating costs of transit networks," Transportation Research Part B: Methodological, vol. 70, pp. 35-46, 2014.

[33] A. Kéri and K. Haase, "Simultaneous vehicle and crew scheduling with trip shifting," in Operation Research Proceedings 2007, pp. 467-472, Springer, Berlin, Germany, 2007.

[34] Z.-g. Liu and J.-s. Shen, "Regional bus operation bi-level programming model integrating timetabling and vehicle scheduling," Systems Engineering-Theory \& Practice, vol. 27, no. 11, pp. 135-141, 2007.

[35] X. Zhoucong, H. Peijia, T. Jing, and L. Liping, "Transit vehicles intelligent scheduling optimization based on the division of characteristic periods," Procedia-Social and Behavioral Sciences, vol. 96, pp. 1502-1512, 2013.

[36] S. Liang, M. Ma, and S. He, "Multiobjective optimal formulations for bus fleet size of public transit under headwaybased holding control," Journal of Advanced Transportation, vol. 2019, Article ID 2452348, 14 pages, 2019.

[37] S. Liang, M. Ma, S. He, and H. Zhang, "The impact of bus fleet size on performance of self-equalize bus headway control method," Proceedings of the Institution of Civil EngineersMunicipal Engineer, vol. 172, no. 4, pp. 246-256, 2018.

[38] Y. Bie, X. Gong, and Z. Liu, "Time of day intervals partition for bus schedule using GPS data," Transportation Research Part C: Emerging Technologies, vol. 60, pp. 443-456, 2015.

[39] Y. Bie, D. Wang, and H. Qi, "Prediction model of bus arrival time at signalized intersection using GPS data," Journal of Transportation Engineering, vol. 138, no. 1, pp. 12-20, 2012.

[40] E. Hans, N. Chiabaut, L. Leclercq, and R. L. Bertini, "Real-time bus route state forecasting using particle filter and mesoscopic modeling," Transportation Research Part C: Emerging Technologies, vol. 61, pp. 121-140, 2015.

[41] H. Yu, D. Chen, Z. Wu, X. Ma, and Y. Wang, "Headway-based bus bunching prediction using transit smart card data,"
Transportation Research Part C: Emerging Technologies, vol. 72, pp. 45-59, 2016.

[42] H. Yu, Z. Wu, D. Chen, and X. Ma, "Probabilistic prediction of bus headway using relevance vector machine regression," IEEE Transactions on Intelligent Transportation Systems, vol. 18, no. 7, pp. 1772-1781, 2017.

[43] H. X. Liu, X. Wu, W. Ma, and H. Hu, "Real-time queue length estimation for congested signalized intersections," Transportation Research Part C: Emerging Technologies, vol. 17, no. 4, pp. 412-427, 2009.

[44] M. Ma, S. Liang, H. Guo, and J. Yang, "Short-term traffic flow prediction using a self-adaptive two-dimensional forecasting method," Advances in Mechanical Engineering, vol. 9, no. 8, Article ID 1687814017719002, 2017.

[45] S. Liang, M. Ma, S. He, H. Zhang, and P. Yuan, "Coordinated control method to self-equalize bus headways: an analytical method," Transportmetrica B: Transport Dynamics, vol. 7, no. 1, pp. 1175-1202, 2019. 


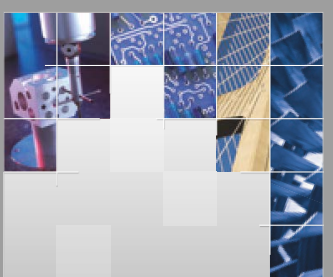

\section{Enfincering}
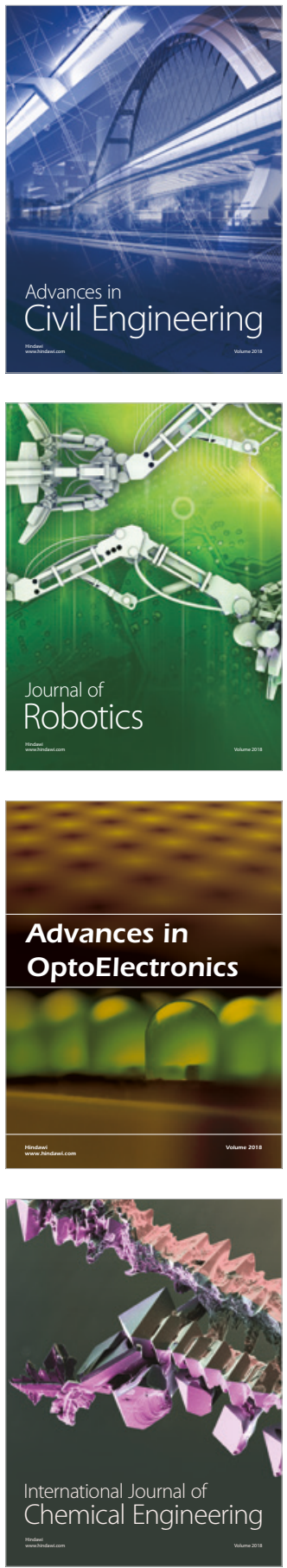

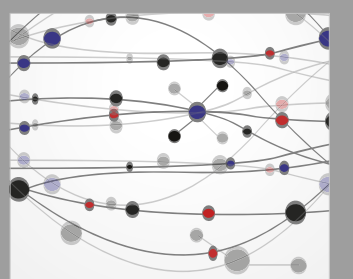

\section{Rotating \\ Machinery}

The Scientific World Journal

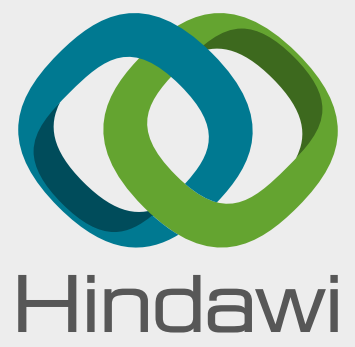

Submit your manuscripts at

www.hindawi.com
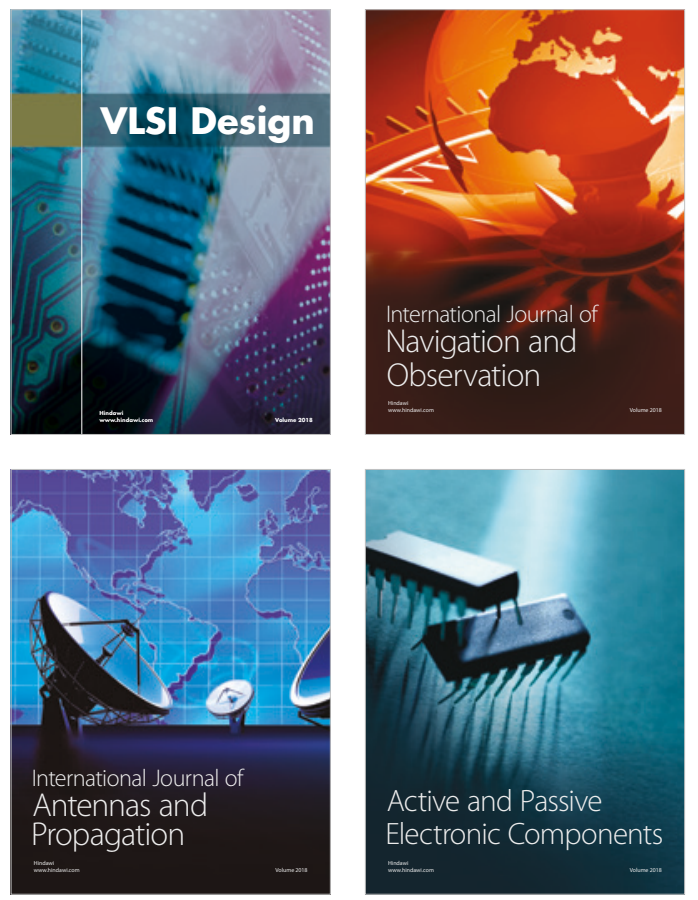
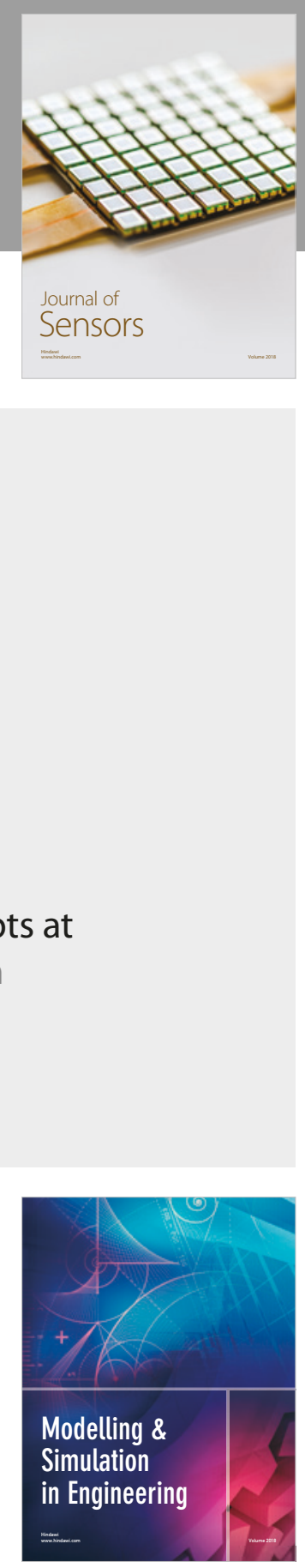

\section{Advances \\ Multimedia}
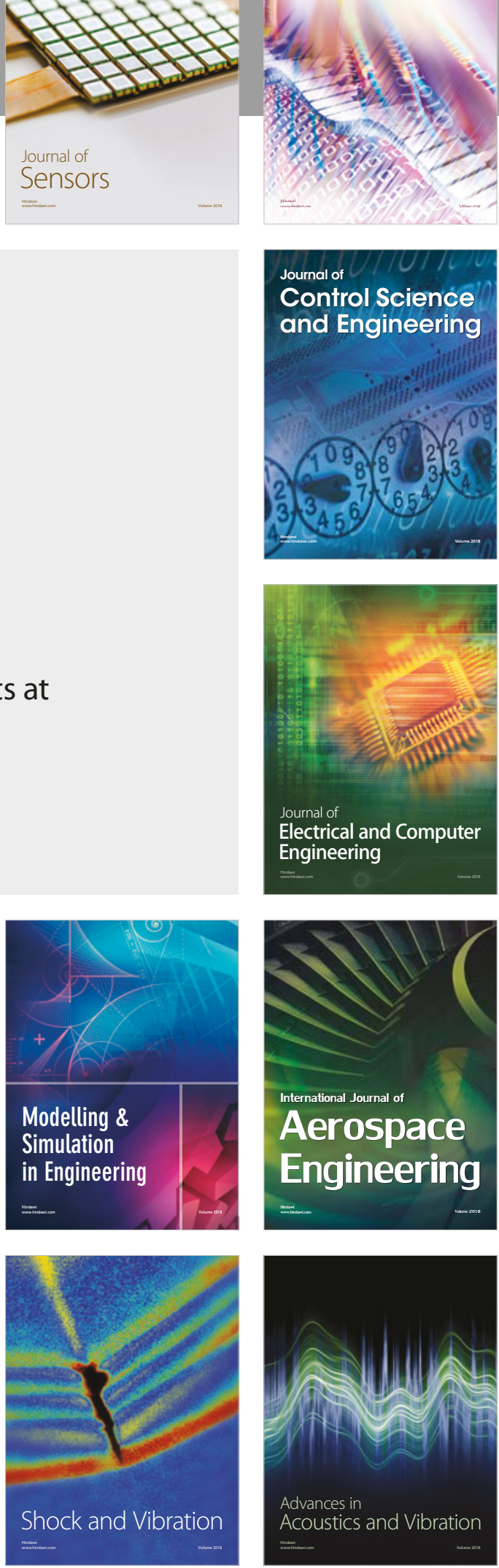